\title{
The Current Status of PrEP in Key Populations
}

\author{
Yi Zhang ${ }^{1,2}$, Zhihai Mao ${ }^{3}$, Yuyang Hua ${ }^{4}$, Shicheng $\mathrm{Gao}^{5}$, Shenghan Lai ${ }^{6}$, Jun Wang ${ }^{1,2,6 \#}$ \\ ${ }^{1}$ Department of Pharmacology, Bioengineering and Food College, Hubei University of Technology, Wuhan, Hubei, \\ China \\ ${ }^{2}$ National 111 Center for Cellular Regulation and Molecular Pharmaceutics, Wuhan, Hubei, China \\ ${ }^{3}$ Huaxin Pharmaceutical Co., Ltd., Tong Cheng City, Hubei, China \\ ${ }^{4}$ Wuhan University of Technology, Wuhan, Hubei, China \\ ${ }^{5}$ Department of Epidemiology, Zhongnan Hospital, Wuhan University, Hubei, China \\ ${ }^{6}$ Department of Pathology, Johns Hopkins School of Medicine, Baltimore, Maryland, USA \\ \#Email: jun.wang.2006@gmail.com
}

\begin{abstract}
Until 2016, the population living with HIV is 36.7 million. Though WHO set the goal to end HIV/AIDS, it is very challenging to stop HIV acquisition in 12 years due to insufficient of medical, economic, social and legal supports. Men who have sex with men (MSM), transgender people, sex workers, and drug users are traditionally classified as the key infected population. Recently, HIV infection in pregnant and breastfeeding women has caused more attention, for HIV hurts two generations in this case. Pre-exposure prophylaxis (PrEP) has been evaluated to be an efficient tool to reduce HIV infection among high-risk population. In this paper, we reviewed the most recent progress of PrEP application in these critical populations who are at substantial risk of HIV acquisition. We also discussed challenges and solution for better prevention of HIV/AIDS.
\end{abstract}

Keywords: HIV, PrEP, MSM, transgender, sex worker, drug user

\section{Introduction}

As one of the biggest public health challenges in the 21st century, human immunodeficiency virus (HIV) or acquired immune deficiency syndrome (AIDS) has caused the death of about 35 million people globally until 2016. Around 36.7 million people were still living with HIV at the end of 2016[1].Each year, there are many newly infected cases. There are four types of typical key population at increased risk of HIV infection: (1) men who have sex with men (MSM), including gay men and prisoners, (2) transgender people, (3) sex workers, and (4) drug users (see Table 1 and Figure 1). Another untypical group of people at high risk are pregnant or breast-feeding women. Distribution of HIV infection is related to the geography. As shown in Table 1, in Asia and Pacific, MSM, sex workers and rest of population are the major infected groups, about $80 \%$ of the whole population. In eastern, southern, western and central Africa, the rest of population is the dominating group. In Eastern Europe and central Asia, drug users and sex workers are the two major groups. In Latin America, Caribbean, Middle East and North Africa, MSM, sex workers and rest of population are the main infected population. In western and central Europe and North America, MSM and sex workers are two major populations.

The World Health Organization (WHO) has set the goal to end AIDS by 2030, which is very challenging. In 2015, about 2.1 million people were newly infected with HIV, which is similar to the 2.2 million infections in 2010. At the same time, due to the application of antiretroviral treatment, the number of death dropped from 1.5 million in 2010 to 1.1 million in 2015 ([2]). Accompanying the significant achievements of antiretroviral therapy, pre-exposure prophylaxis (PrEP) has been recently approved as a critical prevention choice for people at high risk of HIV infection. 
Table 1. Distribution of new HIV infections among groups in different regions of the word in 2014

\begin{tabular}{|c|c|c|c|c|c|c|}
\hline & $\begin{array}{l}\text { Sex } \\
\text { workers }\end{array}$ & $\begin{array}{l}\text { People } \\
\text { who inject } \\
\text { drugs }\end{array}$ & $\begin{array}{l}\text { Gay men and } \\
\text { other men who } \\
\text { have sex with } \\
\text { men }\end{array}$ & $\begin{array}{l}\text { Transgender } \\
\text { people }\end{array}$ & $\begin{array}{l}\text { Clients of sex } \\
\text { workers and other } \\
\text { sexual partners of } \\
\text { key populations }\end{array}$ & $\begin{array}{l}\text { Rest of } \\
\text { population }\end{array}$ \\
\hline Asia and Pacific & $5 \%$ & $13 \%$ & $18 \%$ & $2 \%$ & $24 \%$ & $38 \%$ \\
\hline $\begin{array}{l}\text { Eastern and } \\
\text { Southern Africa }\end{array}$ & $4 \%$ & $2 \%$ & $6 \%$ & $0 \%$ & $9 \%$ & $79 \%$ \\
\hline $\begin{array}{l}\text { Eastern Europe } \\
\text { and central Asia }\end{array}$ & $6 \%$ & $51 \%$ & $6 \%$ & $0 \%$ & $33 \%$ & $4 \%$ \\
\hline $\begin{array}{l}\text { Latin America } \\
\text { and the } \\
\text { Caribbean }\end{array}$ & $6 \%$ & $2 \%$ & $30 \%$ & $3 \%$ & $23 \%$ & $36 \%$ \\
\hline $\begin{array}{l}\text { Middle East and } \\
\text { North Africa }\end{array}$ & $9 \%$ & $28 \%$ & $18 \%$ & $0 \%$ & $41 \%$ & $4 \%$ \\
\hline $\begin{array}{l}\text { Western and } \\
\text { central Africa }\end{array}$ & $15 \%$ & $0.4 \%$ & $2 \%$ & $0 \%$ & $10 \%$ & $73 \%$ \\
\hline $\begin{array}{l}\text { Western and } \\
\text { central Europe } \\
\text { and North } \\
\text { America }\end{array}$ & $1 \%$ & $15 \%$ & $49 \%$ & $0 \%$ & $36 \%$ & $7 \%$ \\
\hline
\end{tabular}

Source: UNAID Special Analysis, 2016

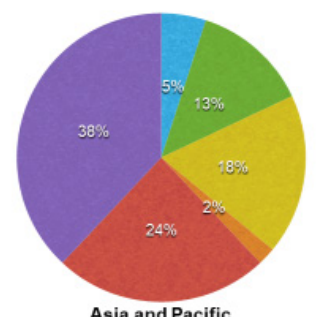

Asia and Pacific

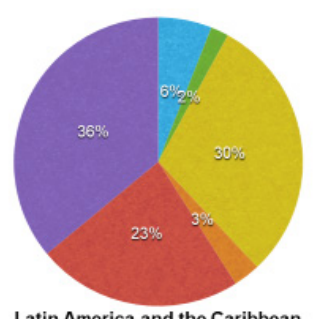

Latin America and the Caribbean

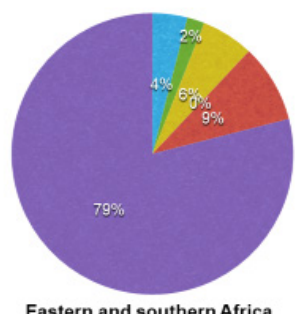

Eastern and southern Africa

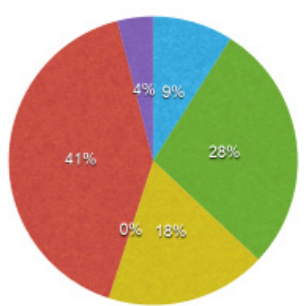

Middle East and North Africa

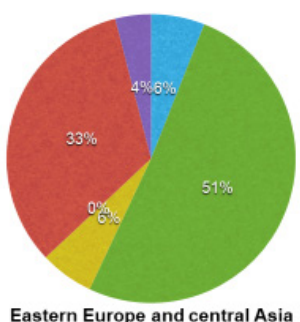

Eastern Europe and central Asia

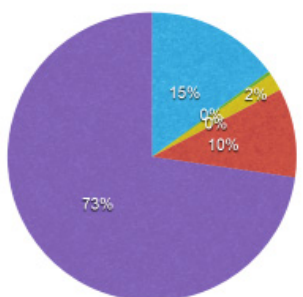

Western and central Africa

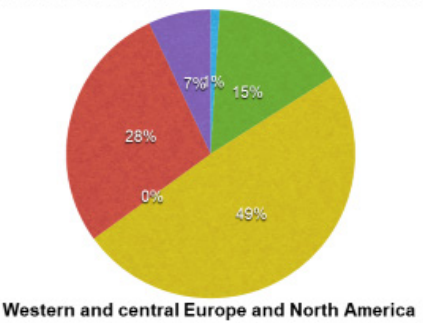

- Sex workers

aymen and other men who hewe sex with men

- Civents of sex works and other sexual partners of key populations

Western and central Europe and North America

Figure 1. Distribution of new HIV infections among population groups in different region of the world in 2014. Source: UNAID special analysis, 2016.

PrEP is the preventative strategy for HIV-uninfected people to take HIV medicines, i.e. oral co-formulated tenofovir disoproxil fumarate-emtricitabine (TDF-FTC), daily to prevent HIV infection ([3-4]). PrEP was 
approved byUS Food and Drug Administration (FDA) in 2012 ([5] and US Public Health Service released the clinical guideline of PrEP in 2014 ([6]). One year later, PrEP was recommended by WHO as a preventative option for people who are at substantial risk of HIV infection. "Substantial risk is defined as HIV incidence greater than three per 100 person-years in the absence of PrEP".([7]).

In order to achieve the goal of ending AIDS in 12 years, it is crucial to make a public health- and people-centered approach. The combined efforts are needed from community educators and advocates, counsellors, leaders, pharmacists, testing providers and PrEP users. Awareness, accessibility, availability, acceptability and quality of PrEP will directly influence the outcome of HIV prevention in these four typical key groups and one atypical group of people. We will report the most recent progress of PrEP in these five subgroups, though there may be overlap among subgroups sometimes.

\section{$2 \quad$ PrEP in MSM}

Since its approval in 2012, the low uptake of PrEP has been observed in the MSM community ([8]). First of all, PrEP is only available in a few countries. Based on surveys among MSM worldwide, awareness and acceptance of PrEP and factors to influence MSM's decision are quite different in high-income, middle-income and low-income countries.

In the USA, a cross-sectional study was performed with 164 people by in-person interview ([9]). Intimacy motivation was found to influence the willingness to take PrEP, when condomless sex is favored. Age and education are the two other factors. In another pilot study of 209 participants without any intervention in the state of Rhode Island has shown that less than half of the HIV-negative people were willing to take PrEP in 2014, even though there was a high prevalence of condomless sex ([8]). Knowledge of PrEP was low and interest in knowing more about PrEP through counseling and education was moderate, though electronic media and brochure was available. One more comprehensive study across USA showed that 1774 people used PrEP between Jan, 2011-March, 2013, with 48\% were female ([10]). This low interest and uptake of PrEP is consistent with other studies done in USA recently ([11]). During the past three decades, medical providers and advocacy groups have kept saying that condom is the most effective way to prevent HIV infection. Therefore, they are hesitating to promote PrEP in MSM population. By educating the MSM community and the general public, uptake of PrEP should be able to increase.

The first study of PrEP in Scotland (UK) showed that both social and psychological barriers are the major barriers. ([12]).PrEP does not prevent hepatitis $\mathrm{C}$ and other sexually transmitted diseases (STD), which causes doubt about the effectiveness of PrEP. Adherence to PrEP with a daily uptake is tedious, which is another concern for these participants in Scotland. Later on, another wider survey with 690 participants published in 2016 showed that only $30 \%$ of MSM were aware of PrEP and $50 \%$ were willing to use it if available ([13]). Young men between 18-25 years old were more likely to accept PrEP than the elder generation.

Among studies focusing on low-income and middle-income countries, MSM participants from South Africa, Uganda, Brazil, Peru, China, India, Kenya, Malaysia, Myanmar, Thailand and Vietnam were surveyed ([14-15]). In most studies, awareness of PrEP was quite low and the average was 30\%. Average acceptability of PrEP was relatively higher, around 64\%. Legal and policy environments play an important role in PrEP acceptability, due to the limited implementation of PrEP and criminalization of MSM in some countries.

\section{$3 \quad$ PrEP in Transgender People}

Though the population of transgender people is smaller than MSM worldwide, unusual disproportionately high prevalence of HIV infection was found in transgender women, this marginalized population ([16]). One meta-analysis in 2013 showed that transgender women had 49 times the odds of getting HIV infection than all other adults at reproductive age ([17]. One study in San Francisco (USA) showed that infected transgender women had the lower ART (antiretroviral therapy) coverage among all high-risk groups ([18]). About 34\% transgender women were reported to be HIV positive in Argentina in 2013, who usually had a history of sex work ([19]). In one survey, about $89 \%$ of 337 participants showed the will to take PrEP. In Thailand, HIV prevalence among transgender women was $11.8 \%$, which is ten times of that in the general population $(1.1 \%)$ ([20]). Participants' risk perception of HIV played a critical role for their willingness to 
accept PrEP, which indicates that education about HIV and PrEP is important for transgender women in Thailand. Among seven clinical trialson efficacy of PrEP in the world, transgender women only comprised $0.2 \%$ of total trial enrollment ([16]).Among transgender youth, only $8.2 \%$ were accessible to PrEP ([21]).MostPrEP clinical trials or projects haven't included transgender women in a meaningful way.

Besides the factors influencing PrEP acceptance in MSM, transgender people encounters more individual barriers in HIV prevention. They are weak in the games of social, political and economic power struggles. In Argentina, discrimination by healthcare workers was a strong negative correlate of willingness to use PrEP. Discrimination, transphobia and violence are the unique barriers for transgender women to access PrEP.As shown in Figure 2, whether trans patient or medical provider may accept or resist each other and PrEP is influenced not only by interpersonal stigma and discrimination, but also by structural and institutional stigma and discrimination. Transgender people usually need to take hormone medicine. Drug-drug interaction between hormone and PrEP medicines lacks sufficient data, which needs urgent biomedical and pharmacological studies. Combined efforts are needed to help transgender people get better accessibility to PrEP.

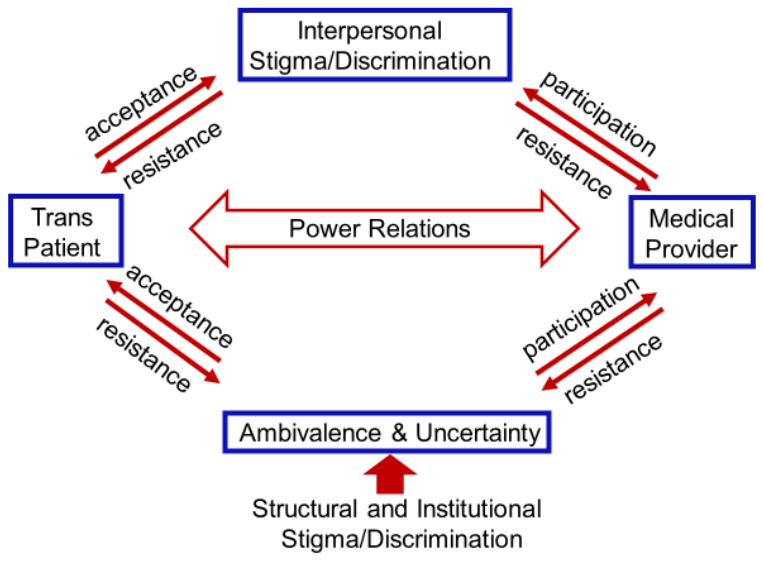

Figure 2. management of stigma/uncertainty in the relations of trans patient and medical provider.

Source: Poteat, T., German, D., Kerrigan, D. (2013) "Managing uncertainty: a grounded theory of stigma in transgender health care encounters" Soc Sci Med., 84, 22-29. doi: 10.1016/j.socscimed.2013.02.019.

\section{$4 \quad$ PrEP in Sex Workers}

Sex workers may be female, male and transgender. Since transgender population has been discussed in the last section and some male sex workers are MSM, this section will focus on female workers. HIV acquisition is disproportionately high among female sex workers, with an overall prevalence of $11.8 \%$ in low- and middle-income countries ([22]). Studies showed that awareness and knowledge of PrEP among sex workers were low, though the willingness to take PrEP was high ([23]). Studies at South Africa showed that HIV infection rate was as high as nearly $75 \%$ among female sex workers ([24]). Among 692 female participants, $49 \%$ were infected. In the HIV-negative group, 93\% were eligible for PrEP. 98\% of this eligible group took PrEP, but only $22 \%$ stayed with PrEP after 12 months. Though the retention rate was low, none of the participants adhering to PreP got HIV infection. Violence and discrimination towards to sex workers have made HIV infection worse ([25]).

\section{$5 \quad$ PrEP in Drug Users}

Similar to sex workers, high risk drug users are traditionally underserved of PrEP. Awareness of PrEP among drugs users are remarkably low, which is in contrast to MSM in North America ([26-28]). One study of $400 \mathrm{HIV}$-negative participants in North America showed a low average acceptability of $56.2 \%$ due to one or several factors among cost, dose, efficiency, side-effects, adherence and treatment-setting ([29]). Cost is the major concern, followed by efficacy and no side-effect. Researchers brought up a method that a combination of biomedical intervention and behavioral intervention would help cut HIV acquisition more 
efficiently among drug users, since many of them encountered neurocognitive impairments ([30]). Another recent study showed that enrollment of the sexual and needle-sharing partners of drug users into PrEP can significantly improve the cost effectiveness of PrEP ([31]).

\section{$6 \quad$ PrEP in Pregnant and Breastfeeding Women}

There is an urgent call for advertising and promoting PrEP among regnant and breastfeeding women, though it is not generally treated as high-risk population $([32]$ : P). Contrary to other high-risk populations, pregnant and breastfeeding women were excluded from most PrEP clinical trials, due to the safety concern for fetuses and infants ([33]). Usually PrEP was discontinued when pregnancy was recognized. However, women at birth age in sub-Saharan Africa are at substantial risk of HIV based on the WHO reports ([34]:), therefore there is an emergent call for HIV prevention in pregnant and breastfeeding women, for HIV hurts two generations in this case.

Recently, several studies in Africa have demonstrated that PrEP is not associated with adverse events during pregnancy $([32,35])$.

Among a study with 50 mother-infant pairs enrolled, median peak concentration of tenofovir and emtricitabine were $3.2 \mathrm{ng} / \mathrm{mL}$ and $212.5 \mathrm{ng} / \mathrm{mL}$, respectively (([36]). In infant plasma, tenofovir was not detectable, and the median concentration of emtricitabine was $13.2 \mathrm{ng} / \mathrm{mL}$. The doses of two compounds in infant's milk were about $<0.01 \%$ and $0.5 \%$ relative dose compared to $6 \mathrm{mg} / \mathrm{kg}$ dose that was proposed for clinical HIV treatment of infant infection. Therefore, these clinical doses of PrEP haven't shown safety concerns. In addition, follow-up study didn't show serious adverse effects.

Another study in African American group at USA showed that more than $10 \%$ of 1637 participants were at increased risk of HIV acquisition, who were eligible for PrEP ([37]). Less than 30\% of these pregnant women had condom protection during sex. It is unknown how many in or around-pregnancy women are eligible for PrEP. Besides PrEP, other preventive HIV interventions are also underused during pregnancy. Based on the Centers for Disease Control (CDC) data, about 468,000 or 0.6\% heterosexual women in USA are eligible for PrEP ([38]).

The consequence of HIV acquisition is a disaster for not only adults, but also for unborn babies and infants. Given these high stakes, PrEP together with other HIV intervention should be more efficiently delivered to HIV-negative pregnant women at risk.

\section{$7 \quad$ Challenges and Solutions}

Since initial recognition of HIV in 1980s, 39 medicines have been approved by FDA for HIV treatment, including Nucleoside Reverse Transcriptase Inhibitors (NRTIs), Non-Nucleoside Reverse Transcriptase Inhibitors (NNRTIs), Protease Inhibitors (PIs), Fusion Inhibitors, CCR5 Antagonists, Integrase Inhibitors, Pharmacokinetic Enhancers and Combination HIV Medicines ([39]). Though ART treatment has gained meaningful progress worldwide, HIV acquisition has only been slightly slowed down. Therefore, effective prevention is critical and urgent for global human health. Efficacy and safety of PrEP has been evaluated in multiple populations, which is appropriate for MSM, transgender people, sex workers, drug users and pregnant/breastfeeding women so far.

However, awareness of PrEP in these key groups is low, especially in transgender, sex worker, drug user and pregnant/breastfeeding women. Cost, efficacy, side effect are the major factors determining people's acceptance. Legal and policy regulation, discrimination from medical workers and society and violence also plays an important role in implementation of PrEP. As part of the HIV prevent package, PrEP needs to work together with other preventative methods, including condom use, STI prevention and testing service, and HIV therapy to achieve the goal ending the AIDS epidemic in 2030.

\section{References}

1. http://www.who.int/gho/hiv/en/

2. Global AIDS response progress reporting 2016; UNAIDS 2016 estimate.

https://aidsreportingtool.unaids.org/static/docs/GARPR_Guidelines_2016_EN.pdf, 
3. Ware, N.C., Wyatt, M.A., Haberer, J.E., Baeten, J.M., Kintu, A., Psaros, C., Safren, S., Tumwesigye, E., Celum, C.L., Bangsberg, D.R. (2012) What's love got to do with it? Explaining adherence to oral antiretroviral pre-exposure prophylaxis for HIV-serodiscordant couples. Journal of acquired immune deficiency syndromes, 59, 463-468. http://dx.doi.org/10.1097/QAI.0b013e31824a060b

4. Namhindo, E.N.; Mei, F.; Cao, R.; Lai, S.; Dai, Y.; Lai, H.; Zhu, M.; Fu, H.; Huang, H.; Wang, J. (2018)PrEP: AIDS-Free Hope in Namibia?International Journal of Biology, 10, 13-16. https://doi.org/10.5539/ijb.v10n1p13

5. Grady D. F.D.A. Advisory Panel Backs Preventive Use of H.I.V. Drug. New York Times 2012 May 10:D5

6. US Public Health Service. Preexposure Prophylaxis for the Prevention of HIV Infection in the United States - 2014 Clinical Practice Guideline, available at: https://www.cdc.gov/hiv/pdf/prepguidelines2014.pdf

7. Preventing HIV during pregnancy and breastfeeding in the context of PrEP, Number of pages: 16 Publication date: July 2017, Languages: English, WHO reference number:

WHO/HIV/2017.09 apps.who.int/iris/bitstream/10665/255866/1/WHO-HIV-2017.09-eng.pdf

8. Merchant, R.C., Corner, D., Garza, E., Guan, W., Mayer, K.H., Brown, L., Chan, P.A. (2016) Preferences for HIV pre-exposure prophylaxis (PrEP) information among men-who-have-sex-with-men (MSM) at community outreach settings. Journal of gay \& lesbian mental health, 20, 21-33. http://dx.doi.org/10.1080/19359705.2015.1105115

9. Gamarel, K.E., Golub, S.A. (2015) Intimacy motivations and pre-exposure prophylaxis (PrEP) adoption intentions among HIV-negative men who have sex with men (MSM) in romantic relationships. Annals of behavioral medicine : a publication of the Society of Behavioral Medicine, 49, 177-186. http://dx.doi.org/10.1007/s12160-014-9646-3

10. Kirby, T., Thornber-Dunwell, M. (2014) Uptake of PrEP for HIV slow among MSM. Lancet, 383, 399-400. http://dx.doi.org/10.1016/S0140-6736(14)60137-9)

11. King, H.L., Keller, S.B., Giancola, M.A., Rodriguez, D.A., Chau, J.J., Young, J.A., Little, S.J., Smith, D.M. (2014) Pre-exposure prophylaxis accessibility research and evaluation (PrEPARE Study). AIDS and behavior, 18, 1722-1725. http://dx.doi.org/10.1007/s10461-014-0845-5

12. Young, I., Flowers, P., McDaid, L.M. (2014) Barriers to uptake and use of pre-exposure prophylaxis (PrEP) among communities most affected by HIV in the UK: findings from a qualitative study in Scotland. BMJ open, 4, e005717. http://dx.doi.org/10.1136/bmjopen-2014-005717

13. Frankis, J., Young, I., Flowers, P., McDaid, L. (2016) Who Will Use Pre-Exposure Prophylaxis (PrEP) and Why?: Understanding PrEP Awareness and Acceptability amongst Men Who Have Sex with Men in the UK--A Mixed Methods Study. PloS one, 11, e0151385. http://dx.doi.org/10.1371/journal.pone.0151385

14. Yi, S., Tuot, S., Mwai, GW., Ngin, C., Chhim, K., Pal, K., Igbinedion, E., Holland, P., Choub, SC., Mburu, G.(2017) doi: 10.7448/IAS.20.1.21580. Awareness and willingness to use HIV pre-exposure prophylaxis among men who have sex with men in low- and middle-income countries: a systematic review and meta-analysis. J Int AIDS Soc. 20, 21580 .

15. Ayala, G., Makofane, K., Santos, G.M., Beck, J., Do, T.D., Hebert, P., Wilson, P.A., Pyun, T., Arreola, S. (2013) Access to Basic HIV-Related Services and PrEP Acceptability among Men Who Have sex with Men Worldwide: Barriers, Facilitators, and Implications for Combination Prevention. Journal of sexually transmitted diseases, 2013, 953123. http://dx.doi.org/10.1155/2013/953123

16. Escudero, D.J., Kerr, T., Operario, D., Socias, M.E., Sued, O., Marshall, B.D. (2015) Inclusion of trans women in pre-exposure prophylaxis trials: a review. AIDS care, 27, 637-641. http://dx.doi.org/10.1080/09540121.2014.986051

17. Baral, S.D., Poteat, T., Stromdahl, S., Wirtz, A.L., Guadamuz, T.E., Beyrer, C. (2013) Worldwide burden of HIV in transgender women: a systematic review and meta-analysis. The Lancet Infectious diseases, 13, $214-222$. http://dx.doi.org/10.1016/S1473-3099(12)70315-8

18. Santos, G.M., Wilson, E.C., Rapues, J., Macias, O., Packer, T., Raymond, H.F. (2014) HIV treatment cascade among transgender women in a San Francisco respondent driven sampling study. Sexually transmitted infections, 90, 430-433. http://dx.doi.org/10.1136/sextrans-2013-051342

19. Zalazar, V., Aristegui, I., Kerr, T., Marshall, B.D.L., Romero, M., Sued, O., Socias, M.E. (2016) High Willingness to Use HIV Pre-Exposure Prophylaxis Among Transgender Women in Argentina. Transgender health, 1, 266-273. http://dx.doi.org/10.1089/trgh.2016.0033

20. Plotzker, R., Seekaew, P., Jantarapakde, J., Pengnonyang, S., Trachunthong, D., Linjongrat, D., Janyam, S., Nakpor, T., Charoenying, S., Mills, S., Vannakit, R., Cassell, M., Phanuphak, P., Lertpiriyasuwat, C., Phanuphak, N. (2017) Importance of Risk Perception: Predictors of PrEP Acceptance Among Thai MSM and TG Women at a Community-Based Health Service. Journal of acquired immune deficiency syndromes, 76, 473-481. 
http://dx.doi.org/10.1097/QAI.0000000000001536

21. Reisner, S.L., Jadwin-Cakmak, L., White Hughto, J.M., Martinez, M., Salomon, L., Harper, G.W. (2017) Characterizing the HIV Prevention and Care Continua in a Sample of Transgender Youth in the U.S. AIDS and behavior, 21, 3312-3327. http://dx.doi.org/10.1007/s10461-017-1938-8

22. Baral, S., Beyrer, C., Muessig, K., Poteat, T., Wirtz, A.L., Decker, M.R., Sherman, S.G., Kerrigan, D. (2012) Burden of HIV among female sex workers in low-income and middle-income countries: a systematic review and meta-analysis. The Lancet Infectious diseases, 12, 538-549. http://dx.doi.org/10.1016/S1473-3099(12)70066-X

23. Restar, A.J., Tocco, J.U., Mantell, J.E., Lafort, Y., Gichangi, P., Masvawure, T.B., Chabeda, S.V., Sandfort, T.G.M. (2017) Perspectives on HIV Pre- and Post-Exposure Prophylaxes (PrEP and PEP) Among Female and Male Sex Workers in Mombasa, Kenya: Implications for Integrating Biomedical Prevention into Sexual Health Services. AIDS education and prevention : official publication of the International Society for AIDS Education, 29, 141-153. http://dx.doi.org/10.1521/aeap.2017.29.2.141

24. Eakle, R., Gomez, G.B., Naicker, N., Bothma, R., Mbogua, J., Cabrera Escobar, M.A., Saayman, E., Moorhouse, M., Venter, W.D.F., Rees, H., Team, T.D.P. (2017) HIV pre-exposure prophylaxis and early antiretroviral treatment among female sex workers in South Africa: Results from a prospective observational demonstration project. PLoS medicine, 14, e1002444. http://dx.doi.org/10.1371/journal.pmed.1002444

25. Wang, Z., Lau, J.T.F., Yang, X., Cai, Y., Gross, D.L., Ma, T., Liu, Y. (2017) Acceptability of Daily Use of Free Oral Pre-exposure Prophylaxis (PrEP) Among Transgender Women Sex Workers in Shenyang, China. AIDS and behavior, 21, 3287-3298. http://dx.doi.org/10.1007/s10461-017-1869-4

26. Young, I., Li, J., McDaid, L. (2013) Awareness and willingness to use HIV pre-exposure prophylaxis amongst gay and bisexual men in Scotland: implications for biomedical HIV prevention. PloS one, 8, e64038.

http://dx.doi.org/10.1371/journal.pone.0064038

27. Goedel, W.C., Halkitis, P.N., Greene, R.E., Duncan, D.T. (2016) Correlates of Awareness of and Willingness to Use Pre-exposure Prophylaxis (PrEP) in Gay, Bisexual, and Other Men Who Have Sex with Men Who Use Geosocial-Networking Smartphone Applications in New York City. AIDS and behavior, 20, 1435-1442. http://dx.doi.org/10.1007/s10461-016-1353-6

28. Ferrer, L., Folch, C., Fernandez-Davila, P., Garcia, A., Morales, A., Belda, J., Susperregui, A.R., Casabona, J., Ad hoc study group for Pr, E.P.a. (2016) Awareness of Pre-exposure Prophylaxis for HIV, Willingness to Use It and Potential Barriers or Facilitators to Uptake Among Men Who Have Sex with Men in Spain. AIDS and behavior, 20, 1423-1433. http://dx.doi.org/10.1007/s10461-016-1379-9

29. Shrestha, R., Karki, P., Altice, F.L., Dubov, O., Fraenkel, L., Huedo-Medina, T., Copenhaver, M. (2017) Measuring Acceptability and Preferences for Implementation of Pre-Exposure Prophylaxis (PrEP) Using Conjoint Analysis: An Application to Primary HIV Prevention Among High Risk Drug Users. AIDS and behavior. http://dx.doi.org/10.1007/s10461-017-1851-1

30.Shrestha, R., Altice, F., Karki, P., Copenhaver, M. (2017) Developing an Integrated, Brief Biobehavioral HIV Prevention Intervention for High-Risk Drug Users in Treatment: The Process and Outcome of Formative Research. Frontiers in immunology, 8, 561. http://dx.doi.org/10.3389/fimmu.2017.00561

31. Fu, R., Owens, D.K., Brandeau, M.L. (2018) Cost-effectiveness of alternative strategies for provision of HIV pre-exposure prophylaxis for people who inject drugs. Aids. http://dx.doi.org/10.1097/QAD.0000000000001747

32. Mofenson, L.M. (2016) Tenofovir Pre-exposure Prophylaxis for Pregnant and Breastfeeding Women at Risk of HIV Infection: The Time is Now. PLoS medicine, 13, e1002133. http://dx.doi.org/10.1371/journal.pmed.1002133

33.VIREAD drug label, revised 02/2016.Gilead,FosterCity,CA,2016. http://www.gilead.com/ /media/Files/pdfs/medicines/liver-disease/viread/viread_pi.pdf.

34. World Health Organization. Consolidated guidelines on the use of antiretroviral drugs for treating and preventing HIV infection - recommendations for a public health approach - secondedition,2016. Geneva, Switzerland: World Health Organization, 2016. http://www.who.int/hiv/pub/arv/arv-2016/en/.

35. Flash, C.A., Dale, S.K., Krakower, D.S. (2017) Pre-exposure prophylaxis for HIV prevention in women: current perspectives. International journal of women's health, 9, 391-401. http://dx.doi.org/10.2147/IJWH.S113675

36. Mugwanya, K.K., Hendrix, C.W., Mugo, N.R., Marzinke, M., Katabira, E.T., Ngure, K., Semiyaga, N.B., John-Stewart, G., Muwonge, T.R., Muthuri, G., Stergachis, A., Celum, C.L., Baeten, J.M. (2016) Pre-exposure Prophylaxis Use by Breastfeeding HIV-Uninfected Women: A Prospective Short-Term Study of Antiretroviral Excretion in Breast Milk and Infant Absorption. PLoS medicine, 13, e1002132. 
http://dx.doi.org/10.1371/journal.pmed.1002132

37. Fruhauf, T., Coleman, J.S. (2017) A Missed Opportunity for U.S. Perinatal Human Immunodeficiency Virus Elimination: Pre-exposure Prophylaxis During Pregnancy. Obstetrics and gynecology, 130, 703-709.

http://dx.doi.org/10.1097/AOG.0000000000002258

38. Smith, D.K., Van Handel, M., Wolitski, R.J., Stryker, J.E., Hall, H.I., Prejean, J., Koenig, L.J., Valleroy, L.A. (2015) Vital Signs: Estimated Percentages and Numbers of Adults with Indications for Preexposure Prophylaxis to Prevent HIV Acquisition--United States, 2015. MMWR Morbidity and mortality weekly report, 64, 1291-1295. http://dx.doi.org/10.15585/mmwr.mm6446a4

39. FDA-Approved HIV Medicines, Last Reviewed: January 23, 2018,

https://aidsinfo.nih.gov/understanding-hiv-aids/fact-sheets/21/58/fda-approved-hiv-medicines) 